\title{
Calmodulin levels in blood cells as a potential biomarker of Alzheimer's disease
}

\author{
Noemí Esteras ${ }^{1}$, Carolina Alquézar ${ }^{1,2}$, Ana de la Encarnación ${ }^{1}$, Alberto Villarejo ${ }^{3}$, Félix Bermejo-Pareja ${ }^{3,4}$ \\ and Ángeles Martín-Requero ${ }^{1,2^{*}}$
}

\begin{abstract}
Introduction: The clinical features of Alzheimer's disease (AD) overlap with a number of other dementias and conclusive diagnosis is only achieved at autopsy. Accurate in-life diagnosis requires finding biomarkers suitable for early diagnosis, as well as for discrimination from other types of dementia. Mounting evidence suggests that AD-dependent processes may also affect peripheral cells. We previously reported that calmodulin (CaM) signaling is impaired in AD lymphoblasts. Here, we address the issue as to whether the assessment of CaM levels in peripheral cells could serve as a diagnostic biomarker.

Methods: A total of 165 subjects were enrolled in the study, including 56 AD patients, 15 patients with mild cognitive impairment, 7 with frontotemporal dementia associated with progranulin mutations, 4 with dementia with Lewy bodies, 20 patients with Parkinson's disease, 10 with amyotrophic lateral sclerosis, 5 with progressive supranuclear palsy, and 48 cognitively normal individuals. CaM levels were then analyzed in lymphoblasts, peripheral blood mononuclear cells and plasma. Receiver operating characteristic (ROC) curve analyses were employed to evaluate the diagnostic performance of CaM content in identifying AD patients.
\end{abstract}

Results: Compared with control individuals, CaM levels were significantly increased in AD cells, but not in the other neurodegenerative disorders. CaM levels differentiated AD from control with a sensitivity of 0.89 and a specificity of 0.82 and were not dependent on disease severity or age. MCl patients also showed higher levels of the protein.

Conclusions: CaM levels could be considered a peripheral biomarker for AD in its early stage and help to discriminate from other types of dementia.

\section{Introduction}

Alzheimer's disease (AD) is the most common form of dementia in older people. The diagnosis of AD is made following clinical criteria and only postmortem autopsy can really confirm the disease $[1,2]$. AD diagnosis is time consuming and requires a combination of clinical assessment, psychological testing, imaging and exclusion of other neurological disorders. The availability of reliable minimally invasive biomarkers for $\mathrm{AD}$ progression, and especially for incipient $\mathrm{AD}$, would be of great interest for an early diagnosis and hopefully to slow disease progression.

\footnotetext{
* Correspondence: amrequero@cib.csic.es

'Department of Cellular and Molecular Medicine, Centro de Investigaciones

Biológicas (CSIC), Ramiro de Maeztu 9, 28040 Madrid, Spain

${ }^{2}$ Centro de Investigación Biomédica en Red de Enfermedades Raras

(CIBERER), Valencia, Spain

Full list of author information is available at the end of the article
}

$\mathrm{AD}$ pathogenesis is not completely understood and diagnosis often occurs after significant neuronal loss and pathology have occurred. However, a variety of postmortem evidence suggests that the pathological hallmarks of $\mathrm{AD}$ begin to occur early in an individual's life. Both disease-specific genetics and environmental factors affect cellular pathways before the clinical onset. Alterations in cellular response to these stressors are not restricted to neurons, representing a systemic pathophysiological process [3-7]. For example, the accumulation of senile plaques in the central nervous system formed by amyloid-beta deposits is the main hallmark of the disease [8], but is also present in the periphery and can be detected in blood [9]. Moreover, systemic changes at the immunological level have been reported to be associated with increased inflammation in the brain $[10,11]$, indicating that the hematopoietic system and the central nervous system are affected similarly by AD-dependent processes. Blood cells, easily 
accessible from patients, may therefore display diseasespecific signature molecules that eventually could serve as biomarkers for AD. A blood-based biomarker would be ideal since venous puncture is a widely accepted procedure with no risk and low cost for sample collection.

Work carried out in our laboratory in the past few years aimed at investigating whether changes in cell cycle-related events could be important in the neurodegenerative process, and to demonstrate the usefulness of peripheral cells from $\mathrm{AD}$ patients to determine $\mathrm{AD}$ pathogenesis $[7,12]$. We reported a functional relationship between $\mathrm{Ca}^{2+} /$ calmodulin $(\mathrm{CaM})$ and the main signaling pathways controlling cell survival or death depending upon growth factor availability in either Epstein-Barr virusimmortalized lymphocytes or freshly isolated lymphocytes [13-15]. These features were considered peripheral signs of the disease, because current evidence relates the process of neuronal apoptosis occurring in $\mathrm{AD}$ to the aberrant re-entry of differentiated neurons into the cell cycle [16-18]. Moreover, we detected significantly increased levels of CaM in AD lymphoblasts [19].

The present work was undertaken to elucidate whether higher $\mathrm{CaM}$ content is a characteristic feature of $\mathrm{AD}$ or whether it may occur in other neurodegenerative disorders. To this end, we determined CaM levels in lymphoblastoid cell lines and peripheral blood mononuclear cells (PBMCs) from nondemented individuals, and from subjects with mild, moderate or severe AD. A small group of mild cognitive impairment (MCI) individuals has been included. MCI is a prodromal phase of AD characterized by the onset of the earliest cognitive symptoms (typically deficits in episodic memory) that do not meet the criteria for dementia [20]. The time and sequence of changes in $\mathrm{AD}$ are considered important factors for improving early diagnosis and treatment $[21,22]$. In addition, we included samples from frontotemporal dementia (FTD) patients, carriers of the splicing mutation c.709-1G>A in the progranulin $(P G R N)$ gene [23], patients with dementia with Lewy bodies (DLB), as well as patients suffering from Parkinson's disease (PD), amyotrophic lateral sclerosis (ALS) and progressive supranuclear palsy (PSP) as other neurodegenerative disorders. We found that assessing the CaM content in lymphocytes could help to discriminate between $\mathrm{AD}$ patients and non- $\mathrm{AD}$ individuals including patients with other dementias or neurodegenerative disorders, and therefore the CaM content of peripheral cells may become a potential biomarker for AD.

\section{Methods}

\section{Subjects}

Healthy controls and patients enrolled in the study were recruited from Hospital Doce de Octubre, Madrid, Spain. Individuals carrying a loss-of-function $P G R N$ mutation, c.709-1G > A [23], suffering from FTD were recruited in
Hospital Donostia, San Sebastián, Spain. The clinical diagnosis of probable $\mathrm{AD}$ was based on the criteria of the National Institute of Neurological and Communicative Disorders and Stroke and the Alzheimer's Disease and Related Disorders Association [1] and on the Diagnostic and Statistical Manual of Mental Disorders IV criteria, and diagnosis required evidence of cognitive decline (neuropsychological test battery, clinical mental examination) as well as evidence of impairment in social or occupational function. The Mini-Mental State Examination was used to assess cognitive function [24]. Classification of mild, moderate and severe degrees of $\mathrm{AD}$ was performed using Diagnostic and Statistical Manual of Mental Disorders III-R criteria. MCI was diagnosed using consensus criteria of the International Working Group on MCI [25]. The diagnosis of FTD was performed by applying consensus criteria as published elsewhere [26]. These individuals carry a loss-of-function $P G R N$ mutation, c.709-1G > A, described previously [23]. Established criteria were applied for the diagnosis of DLB [27], ALS [28], probable PD [29] and PSP [30]. The control group was formed by individuals - in general, family members of the patients - with no signs of neurological disease or cognitive decline.

\section{Blood collection}

This study was approved by the Ethic Committee of Clinical Investigation of Hospital 12 de Octubre and Hospital Donostia and by the Spanish Council of Higher Research Institutional Review Board. Informed consent from all subjects was obtained prior to their participation. Sampling protocols were similar in both clinical centers. Blood samples (approximately $8 \mathrm{ml}$ ) were obtained through antecubital vein puncture in ethylenediamine tetraacetic acid-treated Vacutainer ${ }^{\circledR}$ tubes (BD, Madrid, Spain). Plasma was obtained after centrifugation (2,000 rpm, 10 minutes), apportioned into $500 \mu \mathrm{l}$ aliquots in polypropylene tubes, and stored at $-80^{\circ} \mathrm{C}$.

\section{Isolation of peripheral blood mononuclear cells and establishment of lymphoblastoid cell lines}

PBMCs were isolated on Lymphoprep ${ }^{\text {Tx }}$ density-gradient centrifugation according to the instructions of the manufacturer (Axix-Shield Po CAS, Oslo, Norway). Cells were washed twice with phosphate-buffered saline, counted, and resuspended at the desired concentration.

Establishment of lymphoblastoid cell lines was performed in our laboratory by infecting peripheral blood lymphocytes with the Epstein-Barr virus as described previously [31]. Cells were grown in suspension in $\mathrm{T}$ flasks in an upright position, in approximately $10 \mathrm{ml}$ RPMI 1640 (Gibco, BRL San Francisco, CA, USA) medium that contained $2 \mathrm{mM} \mathrm{L}$-glutamine, $100 \mu \mathrm{g} / \mathrm{ml}$ penicillin/streptomycin and, unless otherwise stated, 10\% (v/v) fetal bovine 
serum, and was maintained in a humidified $5 \%$ carbon dioxide incubator at $37^{\circ} \mathrm{C}$. Fluid was routinely changed every 2 days by removing the medium above the settled cells and replacing it with an equal volume of fresh medium.

\section{Cell extracts}

To prepare cell extracts, cells were harvested, washed in phosphate-buffered saline and then lysed in ice-cold lysis buffer (50 mM Tris pH 7.4, $150 \mathrm{mM} \mathrm{NaCl}, 50 \mathrm{mM} \mathrm{NaF}$, $1 \%$ Nonidet P-40) containing $1 \mathrm{mM}$ sodium orthovanadate, $1 \mathrm{mM}$ phenylmethylsulfonyl fluoride, $1 \mathrm{mM}$ sodium pyrophosphate and protease inhibitor Complete Mini Mixture (Roche, Mannhein, Germany). When preparing cell extracts from PBMCs, cells were pretreated with red blood cell lysis buffer $\left(154 \mathrm{mM} \mathrm{NH}_{4} \mathrm{Cl}, 14 \mathrm{mM} \mathrm{NaHCO}\right.$, $0.1 \mathrm{mM}$ ethylenediamine tetraacetic acid) for 5 minutes, to remove red blood cells from the PBMC pellet. The protein content of the extracts was determined by the BCA protein assay kit (Thermo Scientific Alcobendas, Madrid, Spain).

\section{Western blot analysis}

Protein $(40 \mu \mathrm{g})$ from cell extracts were fractionated on a SDS polyacrylamide gel and transferred to a polyvinylidene fluoride membrane, which was then blocked with 5\% bovine serum albumin and incubated overnight at $4^{\circ} \mathrm{C}$, with primary antibodies at the following dilutions: 1:500 anti-CaM (FL-149; Santa Cruz Biotechnologies, Santa Cruz, CA, USA) and 1:5,000 anti- $\beta$-actin (Sigma Aldrich, Alcobendas, Madrid, Spain). Signals from the primary antibodies were amplified using species-specific antisera conjugated with horseradish peroxidase (Bio-Rad Richmond, CA, USA) and were detected with a chemiluminescent substrate detection system (ECL; Amersham, Uppsala, Sweden). The specificity of the antibodies used in this work was checked by omitting the primary antibodies in the incubation medium. Protein band densities were quantified using Image J software (NIH, Bethesda, MD, USA) after scanning the images with a GS-800 densitometer from Bio-Rad. To compare the results between experiments, all results were normalized by a standard sample included in every western blot. CaM levels of each individual were analyzed at least in two different experiments.

\section{Mass spectrometry analysis of calmodulin}

For CaM identification, $40 \mu \mathrm{g}$ protein from cell lysates were loaded in SDS-PAGE. The gel was then stained with SYPRO ${ }^{\circledR}$ Ruby (Invitrogen, Carlsbad, CA, USA), and the band of interest was cut, destained and washed, and after dithiothreitol reduction and iodoacetamide alkylation was digested with trypsin. Peptides were extracted from the gel and then analyzed in an LTQ Orbitrap Velos (Thermo-Scientific, Alcobendas, Madrid, Spain) coupled to a nanoEasy HPLC (Proxeon, Odense, Denmark). Peptides were first trapped onto a
C18-A1 ASY-Column $2 \mathrm{~cm}$ precolumn (Thermo-Scientific, Alcobendas, Madrid, Spain), and then eluted onto a Biosphere C18 column (C18, inner diameter $75 \mu \mathrm{m}, 15 \mathrm{~cm}$ long, $3 \mu \mathrm{m}$ particle size; NanoSeparations, Nieuwkoop, The Netherlands) and separated using a 80-minute gradient from 3 to 35\% Buffer B (Buffer A, 0.1\% formic acid/2\% acetonitrile; Buffer B, $0.1 \%$ formic acid in acetonitrile) at a flow rate of $250 \mathrm{nl} /$ minute. Mass spectra were acquired in the positive ion mode and in a data-dependent manner selecting the 15 most intense ions for fragmentation using collision-induced dissociation. Full scan spectra (m/z 300 to 1,600 ) were acquired in the Orbitrap with a target value of $1,000,000$ at a resolution of 30,000 (at $\mathrm{m} / \mathrm{z} 400$ ) and MS2 spectra were acquired in the linear ion trap with a target value of 10,000 and normalized collision energy of $38 \%$. Precursor ion charge state screening and monoisotopic precursor selection were enabled. Singly charged ions and unassigned charge states were rejected. Dynamic exclusion was enabled with a repeat count of 1 and exclusion duration of 30 seconds.

Acquired spectra were searched against the human SwissProt database (091813) using the Sequest search engine through PD1.4 (Thermo-Scientific, Alcobendas, Madrid, Spain). As for the search parameters, the precursor and fragment mass tolerance were set to $10 \mathrm{ppm}$ and $0.8 \mathrm{Da}$, respectively. Carbamidomethylation of cysteines was set as a fixed modification, and oxidation of methionines was set as a dynamic modification. Two missed cleavages were allowed. Identified peptides were validated using the Percolator algorithm with a $q$-value threshold of 0.01 .

\section{Enzyme-linked immunosorbent assay analysis}

CaM levels were detected in plasma using a Human Calmodulin Elisa kit from MyBiosource (San Diego, CA, USA) according to the manufacturer's instructions. Then $50 \mu \mathrm{l}$ plasma were added in duplicate to the microtiter wells. Sensitivity of the assay was $1.0 \mathrm{pg} / \mathrm{ml}$. The coefficient of variation in the same lot was $<9 \%$, and in a different lot was $<10 \%$. Spike recovery was 94 to $103 \%$. Linearity was in the following ranges: 1:2 (96 to 101\%), 1:4 (93 to 107\%), 1:8 (92 to 100\%), and 1:16 (96 to 108\%).

\section{Statistical analysis}

Normality was checked with the Kolmogorov-Smirnov test with a Dallal Wilkinson-Lilliefor $p$ value. $p>0.10$ was observed, indicating that the data were consistent with a Gaussian distribution. Parametric tests were therefore used in the statistical analysis.

Statistical significance was estimated by one-way analysis of variance followed by the Tukey's test for multiple comparisons. When appropriate, two-way analysis of variance or Student's $t$ test was performed. Differences were considered significant at $p<0.05$. 
Receiver operating curves (ROC) were drawn by plotting the sensitivity against 1 - specificity for different cutoff values. Areas under the ROC curves were calculated. The best cutoff value to distinguish $\mathrm{AD}$ patients from controls or other diseases was selected to achieve a sensitivity and a specificity $>80 \%$, as described previously [32]. Sensitivity, specificity, and accuracy were calculated for that certain cutoff point. Statistical analyses were performed using GraphPad Prism 6.0 for Mac (San Diego, CA, USA).

\section{Results}

Calmodulin content in Epstein-Barr virus-immortalized lymphocytes from controls and individuals suffering from neurodegenerative disorders

The clinical characterization and demographic data of the study groups of controls and AD, FTD, DLB, PD, ALS and PSP patients are summarized in the upper part of Table 1. Lymphoblastoid cell lines were generated by transformation with the Epstein-Barr virus, and the CaM

Table 1 Summary of the study population

\begin{tabular}{|c|c|c|c|c|c|}
\hline & \multirow[t]{2}{*}{ Number } & \multicolumn{2}{|c|}{ Age } & \multicolumn{2}{|c|}{ Gender } \\
\hline & & Mean & Age range & Male & Female \\
\hline \multicolumn{6}{|c|}{ Lymphoblasts } \\
\hline $\mathrm{HC}$ & 33 & $64 \pm 13$ & (31 to 83 ) & 12 & 21 \\
\hline $\mathrm{MCl}$ & 8 & $73 \pm 6$ & (62 to 82 ) & 4 & 4 \\
\hline \multicolumn{6}{|l|}{$A D$} \\
\hline Total & 35 & $75 \pm 7$ & (59 to 90 ) & 16 & 19 \\
\hline Mild & 18 & $76 \pm 6$ & (60 to 83 ) & 8 & 10 \\
\hline Moderate & 10 & $76 \pm 7$ & (59 to 84 ) & 4 & 6 \\
\hline Severe & 7 & $73 \pm 10$ & (60 to 90 ) & 4 & 3 \\
\hline FTD & 7 & $64 \pm 6$ & (54 to 70 ) & 0 & 7 \\
\hline DLB & 4 & $73 \pm 15$ & (58 to 91 ) & 3 & 1 \\
\hline PD & 20 & $69 \pm 10$ & (49 to 83 ) & 14 & 6 \\
\hline ALS & 10 & $63 \pm 10$ & (47 to 79 ) & 6 & 4 \\
\hline PSP & 5 & $79 \pm 6$ & (72 to 85 ) & 1 & 4 \\
\hline \multicolumn{6}{|c|}{$\begin{array}{l}\text { Peripheral blood } \\
\text { mononuclear cells }\end{array}$} \\
\hline $\mathrm{HC}$ & 15 & $68 \pm 8.3$ & (57 to 81 ) & 4 & 11 \\
\hline $\mathrm{MCl}$ & 7 & $68 \pm 7.6$ & (55 to 76$)$ & 4 & 3 \\
\hline \multicolumn{6}{|l|}{$A D$} \\
\hline Total & 21 & $77 \pm 9$ & (58 to 88 ) & 9 & 12 \\
\hline Mild & 10 & $73 \pm 9$ & (60 to 85 ) & 5 & 5 \\
\hline Moderate & 10 & $79 \pm 8$ & (58 to 86 ) & 4 & 6 \\
\hline Severe & 1 & 88 & 88 & 0 & 1 \\
\hline
\end{tabular}

Values expressed as mean \pm standard deviation. $\mathrm{HC}$, healthy control individuals, no sign of neurological disease; $\mathrm{MCl}$, patients with a diagnosis of mild cognitive impairment; $A D$, patients with a diagnosis of probable Alzheimer's disease; FTD, frontotemporal dementia individuals carrying a lossof-function PGRN mutation; DLB, patients diagnosed for dementia with Lewy bodies; PD, patients with probable Parkinson's disease; ALS, patients with a diagnosis of amyotrophic lateral sclerosis; PSP, patients diagnosed of progressive supranuclear palsy. content was determined by western blotting. To confirm the identity of the immunosignal detected by western blotting as $\mathrm{CaM}$, the band was analyzed by mass spectrometry as described in Methods. Five peptides were identified with high confidence (Additional file 1), confirming that the band detected by western blotting indeed corresponded with CaM.

The cellular levels of CaM in lymphoblasts from individuals of the above study groups are presented in Figure 1. We found that CaM levels were significantly higher in $\mathrm{AD}$ subjects than in controls. In contrast, we did not find differences between cells from controls or patients affected by other forms of dementia, such as DLB, or FTD associated with a loss-of-function PGRN mutation (c-709-1G > A), as well as cells from patients suffering from other neurodegenerative disorders such as PD, ALS or PSP.

To evaluate the diagnostic performance of CaM content as an $\mathrm{AD}$ biomarker, ROC curves were generated (Figure 2). $\mathrm{AD}$ was compared with control, FTD and PD patients. The areas under the ROC curves were $0.945(p<0.0001)$ for the classification control/AD, and $0.979(p<0.0001)$ and 0.944 $(p<0.0001)$ for AD/FTD and AD/PD respectively. Sensitivity, specificity and accuracy were calculated for the optimal cutoff point to distinguish AD patients and were the following: $0.886 / 0.818 / 0.853$ for control/AD; $0.886 / 1 /$ 0.905 for $\mathrm{AD} / \mathrm{FTD}$; and $0.886 / 0.85 / 0.873$ for $\mathrm{AD} / \mathrm{PD}$.

\section{Calmodulin content, age, gender and Alzheimer's disease severity}

To better characterize the difference in CaM content of control and AD lymphoblasts, we studied whether this feature correlated with parameters associated with $\mathrm{AD}$ such as age or disease severity. AD patients were classified in three groups according to Diagnostic and Statistical Manual of Mental Disorders III-R criteria: mild (Mini-Mental State Examination score between 18 and 24), moderate (Mini-Mental State Examination score between 10 and 18), and severe (Mini-Mental State Examination score $<10$ ). A group of patients with amnesic MCI, which could constitute a prodromal stage of $\mathrm{AD}$ because these patients have a high risk of progression to $\mathrm{AD}$ [33], was also included. $\mathrm{CaM}$ content in both control and $\mathrm{AD}$ patients appears to be independent of age, as the difference between the slopes was not significant $(p=0.80)$ (Figure 3A). Likewise, the effect of gender was considered not significant $(p=0.70)$ (Figure 3B). The CaM content in AD patients was also independent of disease severity as there were no differences between lymphoblasts from early or advanced disease patients (Figure 3C). CaM levels were increased even in the MCI group, although to a lesser extent than in the $\mathrm{AD}$ patients $(p=0.06 \mathrm{MCI}$ relative to control individuals, $p=0.26$ when comparing $\mathrm{MCI}$ and mild $\mathrm{AD}$ patients). 


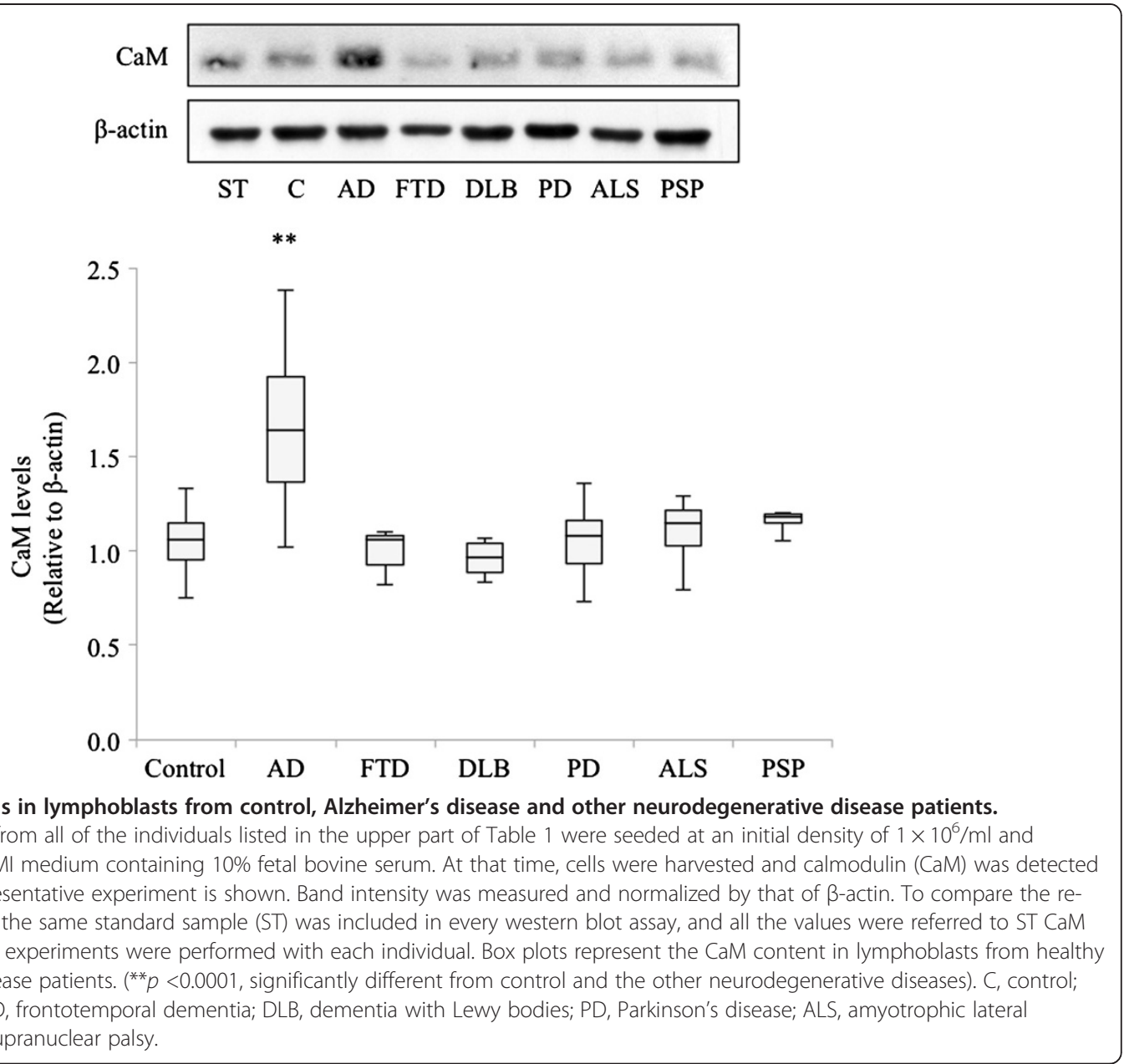

\section{Calmodulin content in PBMCs from control and} Alzheimer's disease subjects

Considering that immortalized lymphocytes are proliferating cells and that CaM has long been implicated in cell cycle regulation $[34,35]$, we were interested in verifying whether differences in CaM levels are also evident between freshly isolated quiescent PBMCs from control and AD patients. Moreover, PBMCs, rather than immortalized lymphocytes, are considered convenient material for molecular diagnosis in clinical practice. For these experiments, we collected samples from 15 control individuals, seven MCI patients and $21 \mathrm{AD}$ patients (see Table 1 , lower part). Approximately $5 \times 10^{6}$ cells derived from control or AD individuals were taken to prepare cell extracts. Figure 4 shows the results of the densitometric analyses of the corresponding immunoblots, revealing higher $\mathrm{CaM}$ content in quiescent mononuclear cells from MCI and AD patients when compared with control cells, thus indicating that the regulation of $\mathrm{CaM}$ content is not affected by the viral transformation.
Analysis of calmodulin content in plasma by enzymelinked immunosorbent assay

Considering the need for a suitable assay for diagnostic purposes, easy to perform in already existing clinical infrastructures for analyses of blood, we were interested in evaluating whether quantitatively determined CaM levels in plasma by enzyme-linked immunosorbent assay would also serve to identify AD patients. A commercially available CaM enzyme-linked immunoassay was used for these experiments (MyBiosource, San Diego, CA, USA). Figure 5 shows that in $\mathrm{AD}$ patients the circulating $\mathrm{CaM}$ levels tended to be higher than in the control group (median (interquartile interval) 321 (315 to 464) vs. 629 (485to 682); $P=0.09$ ), suggesting that measurement of $\mathrm{CaM}$ in plasma could help in AD diagnosis. Further work is needed to replicate this finding in larger and independent populations of patients.

\section{Discussion}

Current therapies and treatments for AD are only symptomatic and the disease remains relentlessly progressive. 


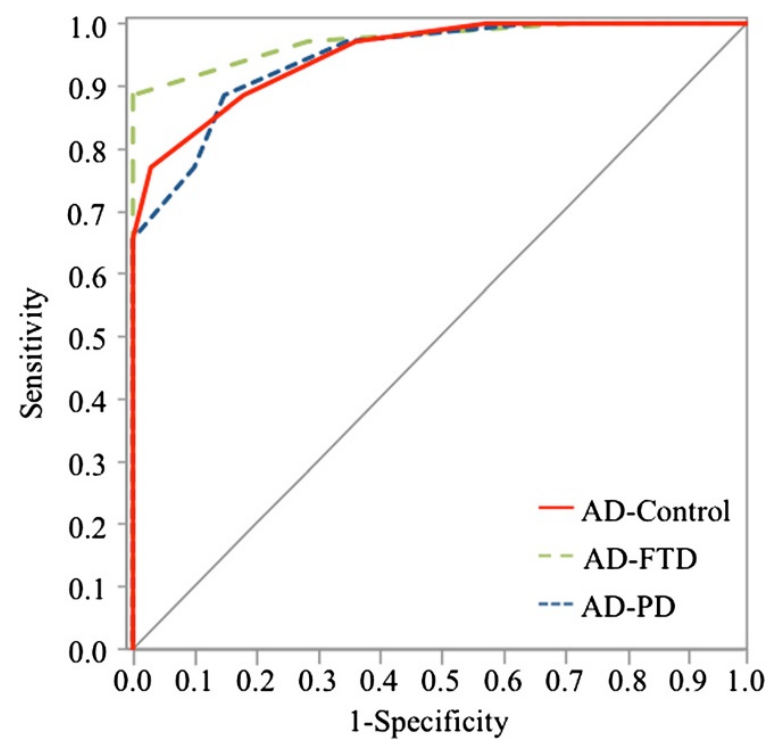

Figure 2 Receiver operating characteristic curve analysis comparing Alzheimer's disease patients and control, frontotemporal dementia or Parkinson's disease patients. Receiver operating characteristic (ROC) curve analysis of differentiation between Alzheimer's disease (AD) patients and healthy controls, between $A D$ and frontotemporal dementia (FTD) patients, and between AD and Parkinson's disease (PD) patients. The area under the ROC curve (AUC) was 0.945 for AD versus control, 0.979 for $A D$ versus FTD, and 0.944 for $A D$ versus PD.

Thus, our need to fully understand the pathogenesis of $\mathrm{AD}$ and to design molecular diagnostics and improved pharmacotherapies is vitally important to the healthcare system. The aim of the present work was to evaluate whether the content of CaM in easily accessible, peripheral cells could support the clinical diagnosis and discriminate $\mathrm{AD}$ from other causes of dementia or even between different stages of the disorder.

We previously reported increased $\mathrm{CaM}$ content in lymphoblasts from $\mathrm{AD}$ patients, as a consequence of impaired proteasomal degradation of the protein [19]. The higher CaM content was associated with impaired cell survival/death mechanisms $[15,36]$. Since cell cycle dysfunction seems to be a convergent point in neurodegenerative diseases [37], it was interesting to determine whether the control failure of CaM levels was commonly involved in neurodegenerative processes or, otherwise, was a disease-specific marker.

We first checked whether freshly isolated lymphocytes from AD patients also show increased levels of CaM as AD lymphoblasts do [19]. Our results indicate that the regulation of $\mathrm{CaM}$ content is not affected by the viral transformation, because higher levels of CaM were indeed found in PBMCs from AD patients than in control cells. This observation highlights the usefulness of
Epstein-Barr virus-transformed lymphocytes as an experimental model.

Our results indicate that increased CaM content is a distinct feature of $\mathrm{AD}$, since it was not observed in cells derived from patients with FTD, carriers of the PGRN mutation c.709-1G > A, DLB, PD, ALS or PSP even considering that cell cycle disturbances had been also described in cells from patients of FTD with PGRN mutations [38] and in other neurodegenerative diseases [37]. What seems to be unique for $\mathrm{AD}$ is the cell sensitivity to CaM-mediated cell survival control, secondary to increased levels of CaM.

Interestingly, no alteration in CaM levels was found in DLB, despite the fact that this dementia shares clinical and pathological characteristics with AD [39].

The changes in CaM content found in AD lymphocytes did not correlate with disease severity, suggesting that this is an early manifestation of the disease. This observation is in agreement with cell cycle theory, which states that cell cycle-related event-induced neurodegeneration is not the result of accumulated loss of neurons but rather an early feature in the instigation of the disease [40]. This lack of correlation would also suggest that the cellular $\mathrm{CaM}$ content is a trait disease marker, not reflecting the disease status. Accordingly, we have also detected increased levels of $\mathrm{CaM}$ in MCI individuals, suggesting the potential of this variable in differentiating MCI and asymptomatic individuals.

ROC curve analyses indicate that the CaM content in peripheral cells is specific and sensitive enough for $\mathrm{AD}$ diagnosis. For the control/AD classification, the area under the ROC curve was 0.945 (95\% confidence interval $0.896,0.994)$ with positive or negative predicted values of $89 \%$ and $88 \%$ respectively. The overall diagnostic accuracy was 0.853 , similar to currently accepted cerebrospinal fluid biomarkers (tau, phospho-tau amyloid-beta 1-42) [41]. In addition, determination of the CaM content in peripheral cells also has the potential of discriminating AD patients from subjects affected by other forms of dementia as well as from other neurodegenerative diseases. Taken together, our results add further support to the usefulness of peripheral lymphocytes for the search of convenient biomarkers for AD [42-44].

Interestingly, a trend towards higher plasma circulating levels of $\mathrm{CaM}$ in $\mathrm{AD}$ subjects versus nondemented individuals was detected by enzyme-linked immunosorbent assay, a more convenient assay in clinical practice. However, further work is needed with a larger number of control and patients affected by AD and other neurodegenerative disorders.

$\mathrm{AD}$ pathogenesis is very complex. According to the cell cycle hypothesis, a dysfunction in the $G_{1} / S$ checkpoint could play a role in instigation of the disease $[5,45,46]$. We previously reported the existence of a 


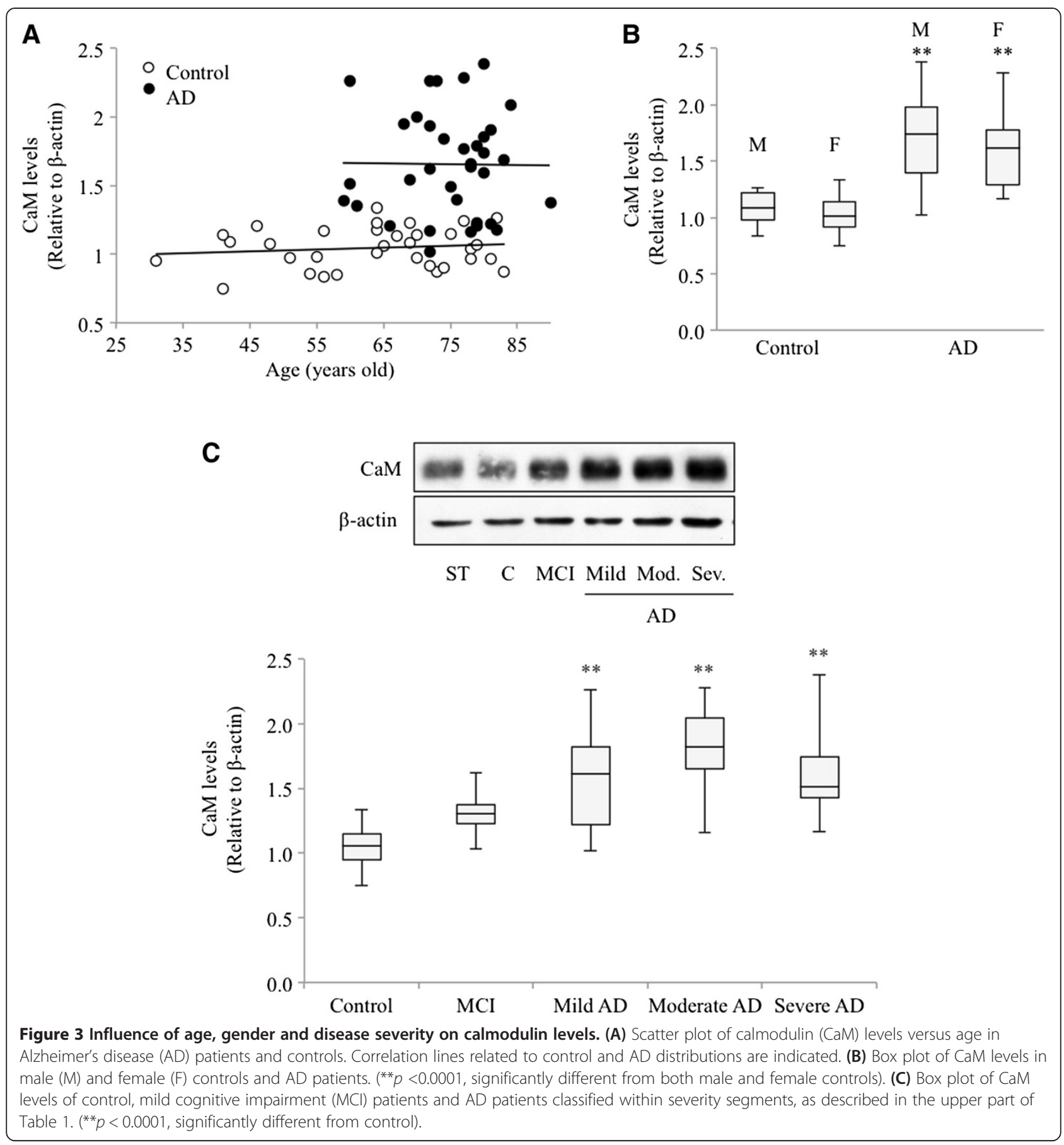

molecular link between decreased levels of the CDK inhibitor $\mathrm{p} 27$, and increased phosphorylation of $\mathrm{pRb}$ protein and proliferation of AD lymphoblasts [12]. On the other hand, the CaM content appears to regulate the rate of p27 degradation in $\mathrm{AD}$ cells through a phosphoinositide-3 kinase/Akt-dependent mechanism [15]. Moreover, higher levels of CaM also correlated with the resistance of $\mathrm{AD}$ cells to serum deprivation-induced apoptosis [36]. CaM thus seems to play a pivotal role in transmitting proliferative/survival signals from the plasma membrane to the nucleus. Whether CaM contributes to cell proliferation or apoptosis depends on cellular CaM levels as well as the presence of growthstimulatory signals. To our knowledge, there is very little information about CaM levels in AD brain; however, impaired CaM-dependent activation of CaMKII 


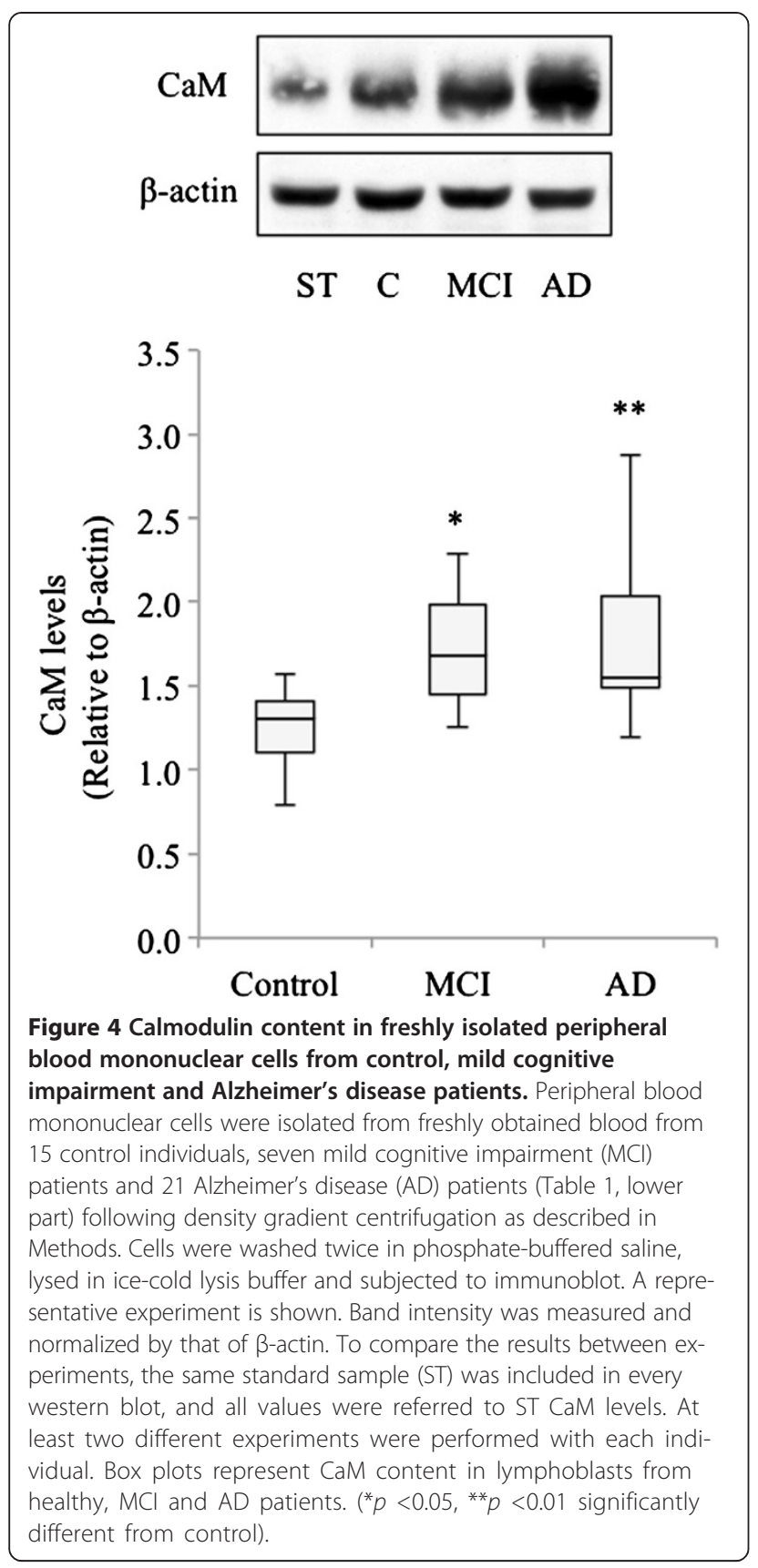

or phosphoinositide-3 kinase/Akt has also been described in AD brain $[47,48]$, and therefore it is tempting to speculate that changes in CaM levels in AD lymphoblasts may be another peripheral sign of the disease. Altered CaM levels in AD brain could play a role in the cell cycle disturbance-induced neuronal apoptosis.

In summary, our study reveals significant changes in $\mathrm{CaM}$ levels in peripheral cells from $\mathrm{AD}$ patients and MCI individuals. Our findings indicate that peripheral cell CaM content has potential diagnostic power, differentiating

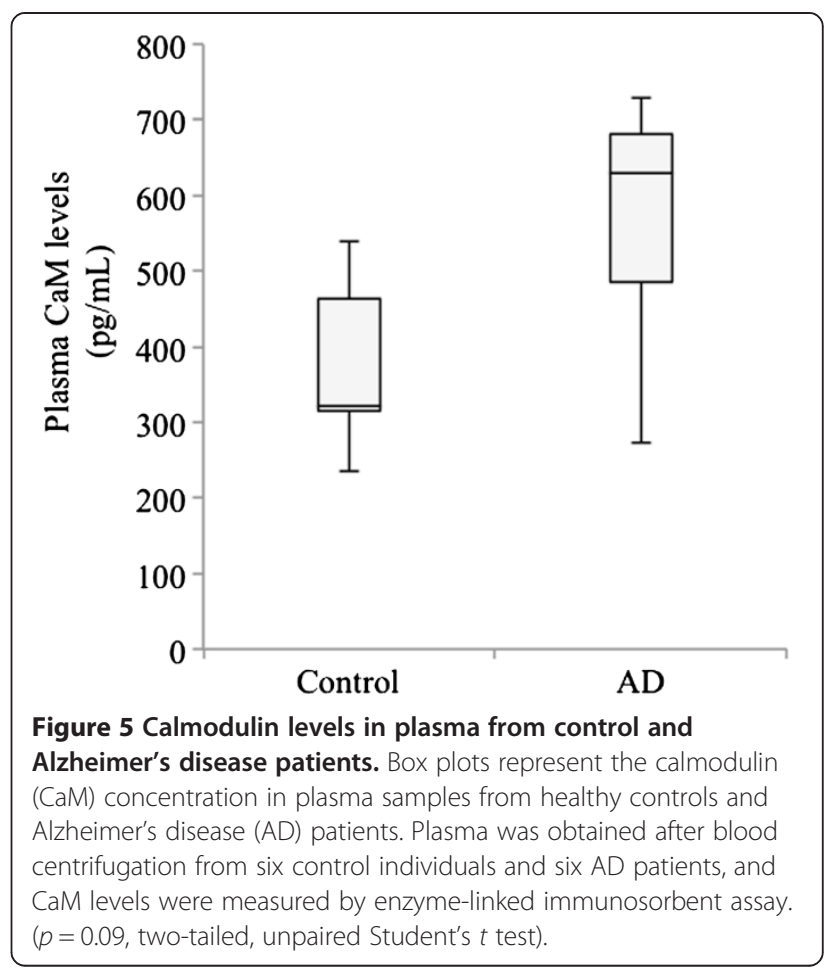

$\mathrm{AD}$ from other types of dementia, as well as from other neurodegenerative disorders. Nevertheless, further work with larger and independent populations of patients will be needed before altered CaM content can be considered a suitable biomarker for AD diagnosis.

\section{Conclusion}

CaM levels measured in peripheral cells could be considered a useful biomarker to help in early diagnosis of $\mathrm{AD}$, enabling one to discriminate $\mathrm{AD}$ from other dementias with high levels of sensitivity and specificity.

Note: This article is part of a series on Peripheral Biomarkers, edited by Douglas Galasko. Other articles in this series can be found at http://alzres.com/series/biomarkers.

\section{Additional file}

Additional file 1: Table S1. Presenting identification of CaM by mass spectrometry.

\section{Abbreviations}

AD: Alzheimer's disease; ALS: Amyotrophic lateral sclerosis; CaM: Calmodulin; DLB: Dementia with Lewy bodies; FTD: Frontotemporal dementia; MCl: Mild cognitive impairment; PBMC: Peripheral blood mononuclear cell;

PD: Parkinson's disease; PGRN: Progranulin; PSP: Progressive supranuclear palsy; ROC: Receiver operating characteristic.

\section{Competing interest}

The authors declare that they have no competing interests. 


\section{Authors' contributions}

NE and AM-R conceived and designed the experiments. NE, CA and AdIE carried out the experimental work. NE analyzed the data, prepared the figures and performed the statistical analysis. AV and FB-P recruited and diagnosed the patients and provided the blood samples. AM-R and NE wrote the manuscript. All authors read and approved the final manuscript.

\section{Acknowledgements}

This work has been supported by grants from Ministerio de Economía y Competitividad (SAF2011-28603) and Fundación Ramón Areces. The authors would like to thank all patients, their families and clinicians involved in this study. The skillful collaboration of Lourdes Sánchez in the sample collection is greatly acknowledged.

\section{Author details}

${ }^{1}$ Department of Cellular and Molecular Medicine, Centro de Investigaciones Biológicas (CSIC), Ramiro de Maeztu 9, 28040 Madrid, Spain. ${ }^{2}$ Centro de Investigación Biomédica en Red de Enfermedades Raras (CIBERER), Valencia, Spain. ${ }^{3}$ Department of Neurology, Hospital Doce de Octubre, Avda de Córdoba s/n, 28041 Valencia, Spain. ${ }^{4}$ Centro de Investigación Biomédica en Red de Enfermedades Neurodegenerativas (CIBERNED), Madrid, Spain.

Received: 4 October 2013 Accepted: 29 October 2013

Published: 7 November 2013

\section{References}

1. McKhann G, Drachman D, Folstein M, Katzman R, Price D, Stadlan EM: Clinical diagnosis of Alzheimer's disease: report of the NINCDS-ADRDA Work Group under the auspices of Department of Health and Human Services Task Force on Alzheimer's Disease. Neurology 1984, 34:939-944.

2. McKhann GM, Knopman DS, Chertkow H, Hyman BT, Jack CR Jr, Kawas CH, Klunk WE, Koroshetz WJ, Manly JJ, Mayeux R, Mohs RC, Morris JC, Rossor MN, Scheltens P, Carrillo MC, Thies B, Weintraub S, Phelps CH: The diagnosis of dementia due to Alzheimer's disease: recommendations from the National Institute on Aging-Alzheimer's Association workgroups on diagnostic guidelines for Alzheimer's disease. Alzheimers Dement 2011, 7:263-269.

3. Cardoso SM, Proenca MT, Santos S, Santana I, Oliveira CR: Cytochrome C oxidase is decreased in Alzheimer's disease platelets. Neurobiol Aging 2004, 25:105-110.

4. Migliore L, Fontana I, Trippi F, Colognato R, Coppede F, Tognoni G, Nucciarone B, Siciliano G: Oxidative DNA damage in peripheral leukocytes of mild cognitive impairment and AD patients. Neurobiol Aging 2005, 26:567-573.

5. Nagy Z, Combrinck M, Budge M, McShane R: Cell cycle kinesis in lymphocytes in the diagnosis of Alzheimer's disease. Neurosci Lett 2002, 317:81-84.

6. Tatebayashi Y, Takeda M, Kashiwagi Y, Okochi M, Kurumadani T, Sekiyama A, Kanayama G, Hariguchi S, Nishimura T: Cell-cycle-dependent abnormal calcium response in fibroblasts from patients with familial Alzheimer's disease. Dementia (Basel, Switzerland) 1995, 6:9-16.

7. Urcelay E, Ibarreta D, Parrilla R, Ayuso MS, Martin-Requero A: Enhanced proliferation of lymphoblasts from patients with Alzheimer dementia associated with calmodulin-dependent activation of the $\mathrm{Na}^{+} / \mathrm{H}^{+}$exchanger. Neurobiol Dis 2001, 8:289-298.

8. Selkoe DJ: Alzheimer's disease results from the cerebral accumulation and cytotoxicity of amyloid beta-protein. J Alzheimers Dis 2001, 3:75-80.

9. Sagare AP, Deane R, Zetterberg $H$, Wallin A, Blennow K, Zlokovic BV: Impaired lipoprotein receptor-mediated peripheral binding of plasma amyloid-beta is an early biomarker for mild cognitive impairment preceding Alzheimer's disease. J Alzheimers Dis 2011, 24:25-34

10. Li M, Shang DS, Zhao WD, Tian L, Li B, Fang WG, Zhu L, Man SM, Chen YH: Amyloid beta interaction with receptor for advanced glycation end products up-regulates brain endothelial CCR5 expression and promotes T cells crossing the blood-brain barrier. J Immunol 2009, 182:5778-5788.

11. Pellicano M, Bulati M, Buffa S, Barbagallo M, Di Prima A, Misiano G, Picone P, Di Carlo M, Nuzzo D, Candore G, Vasto S, Lio D, Caruso C, Colonna-Romano G: Systemic immune responses in Alzheimer's disease: in vitro mononuclear cell activation and cytokine production. J Alzheimers Dis 2010, 21:181-192.
12. Urcelay E, Hermida OG, Saiz-Diaz RA, Bermejo F, Ayuso MS, Martin-Requero A, Delas Cuevas N: $\mathrm{Ca}^{2+} /$ calmodulin-dependent modulation of cell cycle elements $\mathrm{pRb}$ and $\mathrm{p} 27 \mathrm{kip} 1$ involved in the enhanced proliferation of lymphoblasts from patients with Alzheimer dementia. Neurobiol Dis 2003, 13:254-263.

13. Bartolome F, de Las CN, Munoz U, Bermejo F, Martin-Requero A: Impaired apoptosis in lymphoblasts from Alzheimer's disease patients: cross-talk of $\mathrm{Ca}^{2+} /$ calmodulin and ERK1/2 signaling pathways. Cell Mol Life Sci 2007, 64:1437-1448

14. Delas Cuevas N, Munoz U, Bartolome F, Esteras N, Alquezar C, Martin-Requero A: Cell cycle and Alzheimer's disease: studies in non-neuronal cells. J Appl Biomed 2010, 8:121-130.

15. Munoz U, Bartolome F, Bermejo F, Martin-Requero A: Enhanced proteasome-dependent degradation of the CDK inhibitor p27(kip1) in immortalized lymphocytes from Alzheimer's dementia patients. Neurobiol Aging 2008, 29:1474-1484.

16. Lee HG, Casadesus G, Zhu X, Castellani RJ, McShea A, Perry G, Petersen RB, Bajic V, Smith MA: Cell cycle re-entry mediated neurodegeneration and its treatment role in the pathogenesis of Alzheimer's disease. Neurochem Int 2009, 54:84-88.

17. McShea A, Lee HG, Petersen RB, Casadesus G, Vincent I, Linford NJ, Funk JO, Shapiro RA, Smith MA: Neuronal cell cycle re-entry mediates Alzheimer disease-type changes. Biochim Biophys Acta 2007, 1772:467-472.

18. Mosch B, Morawski M, Mittag A, Lenz D, Tarnok A, Arendt T: Aneuploidy and DNA replication in the normal human brain and Alzheimer's disease. J Neurosci 2007, 27:6859-6867.

19. Esteras N, Munoz U, Alquezar C, Bartolome F, Bermejo-Pareja F, Martin-Requero A: Altered calmodulin degradation and signaling in non-neuronal cells from Alzheimer's disease patients. Curr Alzheimer Res 2012, 9:267-277.

20. Albert MS, Dekosky ST, Dickson D, Dubois B, Feldman HH, Fox NC, Gamst A, Holtzman DM, Jagust WJ, Petersen RC, Snyder PJ, Carrillo MC, Thies B, Phelps $\mathrm{CH}$ : The diagnosis of mild cognitive impairment due to Alzheimer's disease: recommendations from the National Institute on Aging-Alzheimer's Association workgroups on diagnostic guidelines for Alzheimer's disease. Alzheimers Dement 2011, 7:270-279.

21. Jack CR Jr, Knopman DS, Jagust WJ, Petersen RC, Weiner MW, Aisen PS, Shaw LM, Vemuri P, Wiste HJ, Weigand SD, Lesnick TG, Pankratz VS, Donohue MC, Trojanowski JQ: Tracking pathophysiological processes in Alzheimer's disease: an updated hypothetical model of dynamic biomarkers. Lancet Neurol 2013, 12:207-216.

22. Jack CR Jr, Knopman DS, Jagust WJ, Shaw LM, Aisen PS, Weiner MW, Petersen RC, Trojanowski JQ: Hypothetical model of dynamic biomarkers of the Alzheimer's pathological cascade. Lancet Neurol 2010, 9:119-128.

23. López de Munain A, Alzualde A, Gorostidi A, Otaegui D, Ruiz-Martínez J, Indakoetxea B, Ferrer I, Pérez-Tur J, Sáenz A, Bergareche A, Barandiarán M, Poza JJ, Zabalza R, Ruiz I, Urtasun M, Fernández-Manchola I, Olasagasti B, Espinal JB, Olaskoaga J, Ruibal M, Moreno F, Carrera N, Martí Massó JF: Mutations in progranulin gene: clinical, pathological, and ribonucleic acid expression findings. Biol Psychiatry 2008, 63:946-952.

24. Folstein MF, Folstein SE, McHugh PR: Mini-mental state. A practical method for grading the cognitive state of patients for the clinician. J Psychiatr Res 1975, 12:189-198.

25. Winblad B, Palmer K, Kivipelto M, Jelic V, Fratiglioni L, Wahlund LO, Nordberg A, Backman L, Albert M, Almkvist O, Arai H, Basun H, Blennow K, de Leon M, DeCarli C, Erkinjuntti T, Giacobini E, Graff C, Hardy J, Jack C, Jorm A, Ritchie K, van Duijn C, Visser P, Petersen RC: Mild cognitive impairment-beyond controversies, towards a consensus: report of the International Working Group on Mild Cognitive Impairment. J Intern Med 2004, 256:240-246

26. McKhann GM, Albert MS, Grossman M, Miller B, Dickson D, Trojanowski JQ: Clinical and pathological diagnosis of frontotemporal dementia: report of the Work Group on Frontotemporal Dementia and Pick's Disease. Arch Neurol 2001, 58:1803-1809.

27. McKeith IG, Dickson DW, Lowe J, Emre M, O'Brien JT, Feldman H, Cummings J, Duda JE, Lippa C, Perry EK, Aarsland D, Arai H, Ballard CG, Boeve B, Burn DJ, Costa D, Del Ser T, Dubois B, Galasko D, Gauthier S, Goetz CG, GomezTortosa E, Halliday G, Hansen LA, Hardy J, Iwatsubo T, Kalaria RN, Kaufer D, Kenny RA, Korczyn A, et al: Diagnosis and management of dementia with Lewy bodies: third report of the DLB Consortium. Neurology 2005, 65:1863-1872 
28. Brooks BR, Miller RG, Swash M, Munsat TL: El Escorial revisited: revised criteria for the diagnosis of amyotrophic lateral sclerosis. Amyotroph Lateral Scler Other Motor Neuron Disord 2000, 1:293-299.

29. Gelb DJ, Oliver E, Gilman S: Diagnostic criteria for Parkinson disease. Arch Neurol 1999, 56:33-39.

30. Litvan I, Bhatia KP, Burn DJ, Goetz CG, Lang AE, McKeith I, Quinn N, Sethi KD, Shults C, Wenning GK: Movement Disorders Society Scientific Issues Committee report: SIC Task Force appraisal of clinical diagnostic criteria for Parkinsonian disorders. Movement Disord 2003, 18:467-486.

31. Ibarreta D, Urcelay E, Parrilla R, Ayuso MS: Distinct pH homeostatic features in lymphoblasts from Alzheimer's disease patients. Ann Neurol 1998, 44:216-222.

32. Consensus report of the Working Group on Molecular and Biochemical Markers of Alzheimer's Disease: The Ronald and Nancy Reagan Research Institute of the Alzheimer's Association and the National Institute on Aging Working Group. Neurobiol Aging 1998, 19:109-116.

33. Gauthier S, Reisberg B, Zaudig M, Petersen RC, Ritchie K, Broich K, Belleville S, Brodaty $H$, Bennett D, Chertkow H, Cummings JL, de Leon M, Feldman $H_{\text {, }}$ Ganguli M, Hampel H, Scheltens P, Tierney MC, Whitehouse P, Winblad B, International Psychogeriatric Association Expert Conference on mild cognitive impairment: Mild cognitive impairment. Lancet 2006, 367:1262-1270.

34. Davidkova G, Zhang SP, Nichols RA, Weiss B: Reduced level of calmodulin in PC12 cells induced by stable expression of calmodulin antisense RNA inhibits cell proliferation and induces neurite outgrowth. Neuroscience 1996, 75:1003-1019.

35. Rasmussen CD, Means AR: Calmodulin as a regulator of cell growth and gene expression. Soc Gen Physio/ Ser 1987, 42:287-293.

36. Esteras N, Alquezar C, Bermejo-Pareja F, Bialopiotrowicz E, Wojda U, Martin-Requero A: Downregulation of extracellular signal-regulated kinase $1 / 2$ activity by calmodulin KII modulates p21Cip1 levels and survival of immortalized lymphocytes from Alzheimer's disease patients. Neurobiol Aging 2013, 34:1090-1100.

37. Husseman JW, Nochlin D, Vincent I: Mitotic activation: a convergent mechanism for a cohort of neurodegenerative diseases. Neurobiol Aging 2000, 21:815-828.

38. Alquezar C, Esteras N, Bartolome F, Merino JJ, Alzualde A, de Munain AL, Martin-Requero A: Alteration in cell cycle-related proteins in lymphoblasts from carriers of the c.709-1G > A PGRN mutation associated with FTLD-TDP dementia. Neurobiol Aging 2012, 33:e427-e420.

39. McKeith IG, Burn DJ, Ballard CG, Collerton D, Jaros E, Morris CM, McLaren A, Perry EK, Perry R, Piggott MA, O'Brien JT: Dementia with Lewy bodies. Semin Clin Neuropsychiatry 2003, 8:46-57.

40. Yang $Y$, Varvel NH, Lamb BT, Herrup K: Ectopic cell cycle events link human Alzheimer's disease and amyloid precursor protein transgenic mouse models. J Neurosci 2006, 26:775-784.

41. Blennow K, Hampel H: CSF markers for incipient Alzheimer's disease. Lancet Neurol 2003, 2:605-613.

42. Racchi M, Uberti D, Govoni S, Memo M, Lanni C, Vasto S, Candore G, Caruso C, Romeo L, Scapagnini G: Alzheimer's disease: new diagnostic and therapeutic tools. Immun Ageing 2008, 5:7.

43. Stieler J, Grimes R, Weber D, Gartner W, Sabbagh M, Arendt T: Multivariate analysis of differential lymphocyte cell cycle activity in Alzheimer's disease. Neurobiol Aging 2012, 33:234-241

44. Tan M, Wang S, Song J, Jia J: Combination of p53(ser15) and p21/p21 (thr145) in peripheral blood lymphocytes as potential Alzheimer's disease biomarkers. Neurosci Lett 2012, 516:226-231.

45. Zhou X, Jia J: P53-mediated G(1)/S checkpoint dysfunction in lymphocytes from Alzheimer's disease patients. Neurosci Lett 2010, 468:320-325.

46. Munoz U, de Las CN, Bartolome F, Hermida OG, Bermejo F, Martin-Requero A: The cyclopentenone 15 -deoxy-delta(12,14)-prostaglandin J2 inhibits G1/S transition and retinoblastoma protein phosphorylation in immortalized lymphocytes from Alzheimer's disease patients. Exp Neurol 2005, 195:508-517.
47. McKee AC, Kosik KS, Kennedy MB, Kowall NW: Hippocampal neurons predisposed to neurofibrillary tangle formation are enriched in type II calcium/calmodulin-dependent protein kinase. J Neuropathol Exp Neurol 1990, 49:49-63.

48. Rickle A, Bogdanovic N, Volkman I, Winblad B, Ravid R, Cowburn RF: Akt activity in Alzheimer's disease and other neurodegenerative disorders. Neuroreport 2004, 15:955-959.

doi:10.1186/alzrt219

Cite this article as: Esteras et al:: Calmodulin levels in blood cells as a potential biomarker of Alzheimer's disease. Alzheimer's Research \& Therapy 2013 5:55.

\section{Submit your next manuscript to BioMed Central and take full advantage of:}

- Convenient online submission

- Thorough peer review

- No space constraints or color figure charges

- Immediate publication on acceptance

- Inclusion in PubMed, CAS, Scopus and Google Scholar

- Research which is freely available for redistribution

Submit your manuscript at www.biomedcentral.com/submit
C) Biomed Central 